\title{
Synthesis of Poly(cyclic orthoester)s by the One-Pot Reaction of Potassium Perfluoroalkylcarboxylates with Epibromohydrin Using Two-Step Catalysis of Quaternary Onium Salts
}

\author{
Atsushi Kameyama, Hiroyuki Hashikawa, Nobuyuki KiJima, \\ and Tadatomi NisHIKUBO* \\ Department of Applied Chemistry, Kanagawa University, Rokkakubashi, \\ Kanagawa-ku, Yokohama 221, Japan
}

(Received June 12, 1995)

\begin{abstract}
KEY WORDS Perfluoroalkylcarboxylates / Epibromohydrin / Poly(cyclic orthoester)s / Phase Transfer Catalysts / Quaternary Onium Salts / Crown Ethers / Two-Step Catalysis /
\end{abstract}

Quaternary onium salts and crown ethers are exteremely useful as phase transfer catalysts (PTC) in synthetic organic chemistry and polymer synthesis. Our research group has studied in detail chemical modifications ${ }^{1}$ of polymers such as poly(chloromethylstyrene) using PTC. Moreover, photosensitive polymers $^{2}$ and photoresponsive polymers ${ }^{3}$ for solar energy storage were successfully synthesized by the chemical modifications using PTC.

Meanwhile, the authors reported new catalytic activity of quaternary onium salts or crown ether complexes on the addition reactions of cyclic ethers or sulfides with carboxylic acid derivatives. ${ }^{4}$ For example, the addition reaction of oxiranes ${ }^{5}$ or thiiranes 6 with $S$-phenyl carboxylates using the aforementioned catalysts proceeded smoothly and regioselectively to give the corresponding products. As an application, new acyl group transfer polymerization ${ }^{7}$ of thiiranes was successfully achieved using carboxylic acid derivatives as initiatores and quaternary onium salts or crown ether complexes as catalysts.

More recently, we reported a unique cycloaddition reaction ${ }^{8}$ of oxiranes with alkyl perfluoroalkylcarboxylates using the catalysts, which provide five-membered cyclic orthoesters. It was also found that although the reaction of oxiranes with alkyl carboxylates such as ethyl acetate or ethyl benzoate did not proceed at all, the reaction with alkyl perfluoroalkylcarboxylates proceeded very smoothly in the presence of the catalysts. This means that perfluoroalkyl groups activate the adjacent carbonyl group to react the oxiranes. Furthermore, the cycloaddition reaction was successfully applied for the synthesis of poly(cyclic orthoester) $\mathrm{s}^{9}$ by the cycloaddition polymerization of bis(oxirane)s with bifunctional trifluorocarboxylates. It was also suggested that those cycloadditon reactions using conventional Lewis acids such as $\mathrm{BF}_{3} \cdot \mathrm{OEt}_{2}$ did not proceed because of the acid-induced ring-opening polymerization of the used oxiranes, even though synthesis of orthoesters by the acidcatalyzed reaction of oxiranes with certain carbonyl compounds has been known. Thus, it should be emphasized that an advantage of the reactions using quaternary onium salts or crown ether complexes is the selective transformation of cyclic ethers under neutral condi-

* To whom all correspondence should be addressed. 


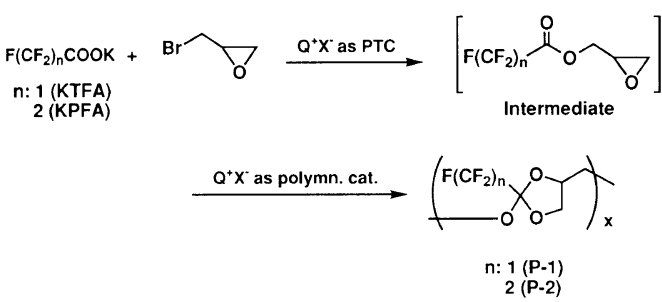

Scheme 1.

tions.

From this background, we designed a one-pot synthesis of poly(cyclic orthoester)s by the reaction of perfluoroalkylcarboxylate derivatives with a oxirane based on a two-step catalysis of quaternary onium salts or crown ether complexes. In the reaction, glycidyl ester derivatives as intermediates were initially produced by phase transfer catalysis of those catalysts. Then, the cycloaddition polymerization of the formed glycidyl ester derivatives proceeds to give the corresponding poly(cyclic orthoester)s.

In this paper, we wish to report new synthesis of poly(cyclic orthoester)s by one-pot reaction of potassium perfluoroalkylcarboxylates with epibromohydrin using quaternary onium salts as phase transfer catalysts and polymerization catalysts.

The reaction of potassium trifluoroacetate (KTFA) with EBH was conducted using $8 \mathrm{~mol} \%$ of tetrabutylammonium bromide (TBAB) as a catalyst in various solvents at $90^{\circ} \mathrm{C}$ for $24 \mathrm{~h}$. The results are summarized in Table I. When the reaction was carried out in low polar solvents such as anisole or chlorobenzene, the corresponding polymer was not obtained. This means that the first nucleophilic substitution reaction of KTFA with EBH catalyzed by TBAB as PTC scarcely proceeded in the low polar solvents. On the other hand, the reaction proceeded smoothly in $N$-methyl-2-pyrrolidone (NMP) to afford the targeted polymer with number-average molecular weight $\left(\bar{M}_{n}\right)$ of about 9000 in $73 \%$ yield. The reaction was efficiently enhanced in $\mathrm{N}, \mathrm{N}$-dimethylacetamide or tetrahydrofuran
Table I. Synthesis of $\mathrm{P}-1$ by one-pot reaction of KTFA with EBH using TBAB in various solvents ${ }^{\mathrm{a}}$

\begin{tabular}{cccc}
\hline Solvent $^{\mathrm{b}}$ & Yield $/ \%^{\mathrm{c}}$ & $\bar{M}_{\boldsymbol{n}}{ }^{\mathrm{d}}$ & $\bar{M}_{\boldsymbol{w}} / \bar{M}_{n}$ \\
\hline Anisole & 0 & - & - \\
Chlorobenzene & 0 & - & - \\
THF & 77 & 11600 & 1.44 \\
NMP & 73 & 8600 & 1.27 \\
DMAc & 64 & 11000 & 1.31 \\
DMSO & 40 & 11000 & 1.58
\end{tabular}

a The reaction was carried out with $\mathrm{KTFA}(3 \mathrm{mmol})$ and EBH $(3 \mathrm{mmol})$ using TBAB in solvent $(1 \mathrm{ml})$ at $90^{\circ} \mathrm{C}$ for 24 h. ${ }^{\text {b }}$ THF, tetrahydrofuran; NMP, $N$-methyl-2-pyrrolidone, DMAc, $N, N$-dimethylacetamide; DMSO, dimethyl sulfoxide. ${ }^{\mathrm{c}}$ Insoluble parts in $n$-hexane. ${ }^{\mathrm{d}}$ Estimated by GPC based on polystyrene standards.

Table II. Effect of catalysts on the reaction of KTFA with EBH using TBAB ${ }^{a}$

\begin{tabular}{lcrc}
\hline \multicolumn{1}{c}{ Catalyst $^{\mathrm{b}}$} & Yield/\% & \multicolumn{1}{c}{$\bar{M}^{\mathrm{c}}{ }^{\mathrm{d}}$} & $\bar{M}_{\boldsymbol{w}} / \bar{M}_{n}$ \\
\hline None & 56 & 6700 & 1.37 \\
TBAC & 60 & 11900 & 1.32 \\
TBAB & 73 & 8600 & 1.27 \\
15-C-5 & 54 & 10400 & 1.29 \\
18-C-6 & 59 & 10100 & 1.32
\end{tabular}

${ }^{\text {a }}$ The reaction was carried out with KTFA $(3 \mathrm{mmol})$ and EBH $(3 \mathrm{mmol})$ using catalyst in NMP $(1 \mathrm{ml})$ at $90^{\circ} \mathrm{C}$ for $24 \mathrm{~h}^{\mathrm{b}}{ }^{\mathrm{T}} \mathrm{TBAC}$, tetrabutylammonium chloride; TBAB, tetrabutylammonium bromide; 15-C-5, 15-crown-5; 18-C-6, 18-crown-6. ${ }^{\mathrm{c}}$ Insoluble parts in $n$-hexane. ${ }^{\mathrm{d}}$ Estimated by GPC based on polystyrene standards.

to give the polymer with $\bar{M}_{n}$ of 11000 in moderate yields. Therefore, it was suggested that the phase transfer catalysis of the substitution reaction of KTFA with EBH is the important process on the one-pot reaction.

The effect of the catalysts on the reaction of KTFA with EBH was examined in NMP at $90^{\circ} \mathrm{C}$ for $24 \mathrm{~h}$ (Table II). When the reaction was carried out without catalysts, the polymer with $\bar{M}_{n}$ of 6700 was obtained in $56 \%$ yield. It seems that the substitution reaction of KTFA with EBH proceeds gradually in the high-polar solvent to form the corresponding intermediate, glycidyl trifluoroacetate, eliminating $\mathrm{KBr}$ in the first step, and then the produced $\mathrm{KBr}$ 
catalyzed $^{10}$ the following cycloaddition polymerization of the intermediate.

The reaction was enhanced by the addition of quaternary onium salts or crown ethers under the same conditions. When the reaction was carried out using 18-crown-6 (18-C-6), the corresponding polymer with $\bar{M}_{n}$ of 10000 was obtained. The increase of the molecular weight might be ascribed to the incorporation of the produced $\mathrm{KBr}$ by $18-\mathrm{C}-6$ to form the corresponding crown ether complex. Tetrabutylammonium chloride (TBAC) and TBAB also enhanced the reaction, in particular, the reaction using TBAC gave the polymer with the highest $\bar{M}_{n}$ of 12000 . This means that quaternary onium salts efficiently catalyze the substitution reaction in the first step as PTC followed by polymerization in the second step during the reaction of KTFA with $\mathrm{EBH}$.

The structure of the resulting polymer (P-1) was ascertained by IR and ${ }^{1} \mathrm{H}$ NMR spectroscopies. The IR spectrum showed peaks at $2962 \mathrm{~cm}^{-1}$ due to $\mathrm{C}-\mathrm{H}$ stretching, at $1280 \mathrm{~cm}^{-1}$ due to $\mathrm{C}-\mathrm{F}$ stretching, and at 1184 and $1116 \mathrm{~cm}^{-1}$ due to the $\mathrm{C}-\mathrm{O}-\mathrm{C}$ stretching. Furthermore, no peaks due to carbonyl group and oxirane ring were observed in the corresponding regions. As shown in Scheme 2., ${ }^{1} \mathrm{H}$ NMR spectral data was identified with reference to the spectral data of a poly(cyclic orthoester) previously reported by Hall. ${ }^{11}$ Thus, it was proved that the targeted polymer with five-membered cyclic orthoester in the main chain was obtained by the one-pot

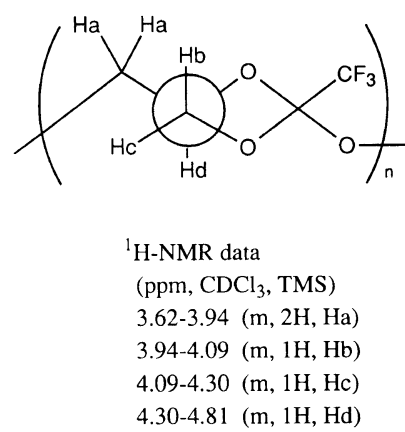

Scheme 2. reaction of KTFA with EBH.

The one-pot reactions of other potassium perfluoroalkylcarboxylates with EBH using TBAB were also carried out in NMP under the similar conditions. The reaction of $\mathrm{EBH}$ with potassium pentafluoropropionate (KPFA) proceeded to give the corresponding polymer (P-2) with $\bar{M}_{n}$ of 8000 .

In summary, it was demonstrated that the one-pot reaction of potassium perfluoroalkylcarboxylates with epibromohydrin proceeded successfully using quaternary onium salts to give new polymers with five-membered cyclic orthoester structures in the backbones. The quaternary onium salts act as phase transfer catalysts in the first step and polymerization catalysts during the one-pot reaction.

\section{REFERENCES}

1. a) T. Nishikubo, T. Iizawa, K. Kobayashi, and M. Okawara, Makromol. Chem. Rapid Commun., 1, 765 (1980); b) T. Nishikubo and T. Iizawa, J. Syn. Org. Chem. Jpn., 51, 157 (1993).

2. a) T. Nishikubo, T. Iizawa, and M. Hasegawa, $J$. Polym. Sci., Polym. Lett. Ed., 19, 113 (1981); b) T. Iizawa, T. Nishikubo, E. Takahashi, and $\mathrm{M}$. Hasegawa, Makromol. Chem., 184, 2297 (1983).

3. a) T. Nishikubo, T. Shimokawa, and A. Sahara, Macromolecules, 22, 8 (1989); b) K. Kishi, H. Ban-no, A. Kameyama, and T. Nishikubo, Kobunshi Ronbunshu, 51, 295 (1994); c) T. Nishikubo, A. Kameyama, K. Kishi, and C. Hijikata, Reactive Polymers, 24, 65 (1994).

4. T. Nishikubo and A. Kameyama, Prog. Polym. Sci., 18, 969 (1993).

5. a) T. Nishikubo, T. Iizawa, M. Shimojo, and $\mathbf{M}$. Shi-ina, J. Org. Chem., 55, 2536 (1990). b) T. Nishikubo, T. Kato, Y. Sugimoto, M. Tomoi, and S. Ishigaki, Macromolecules, 23, 3406 (1990).

6. A. Kameyama, M. Kiyota, and T. Nishikubo, Tetrahedron Lett., 35, 4571 (1994).

7. A. Kameyama, K. Shimotsuma, and T. Nishikubo, Macromol. Rapid Commun., 15, 335 (1994).

8. A. Kameyama, Y. Hatakeyama, and T. Nishikubo, Tetrahedron Lett., 36, 2781 (1995).

9. A. Kameyama, K. Mochida, and T. Nishikubo, Macromolecules, 28, 3490 (1995).

10. T. Nishikubo, Y. Sugimoto, and K. Sato, Nippon Kagaku Kaishi, 1506 (1991).

11. Y. Yokoyama, A. Buyle Padias, Fr. De Blauwe, and H. K. Hall Jr., Macromolecules, 13, 252 (1980). 